\title{
The Use of Runs Test in Amman Stock Exchange
}

\author{
Sameer Elbarghouthi \\ Department of Accounting, Alzaytoonha University of Jordan \\ E-mail: samabr2002@yahoo.com \\ Amer Qasim \\ Department of Accounting, American University of Madaba \\ E-mail: a.qasim@aum.edu.jo \\ Mohammed Yassin \\ Department of Accounting, Alzaytoonah University of Jordan \\ E-mail: mmmy1974@yahoo.com
}

Received: October 5, 2011

Accepted: November 17, 2011

Published: February 1, 2012

doi:10.5539/ibr.v5n2p159

URL: http://dx.doi.org/10.5539/ibr.v5n2p159

\begin{abstract}
This paper applies runs test - runs up and down, distributions of runs by length, and runs above and below -to examine whether ASE is weak form efficient. The empirical results obtained in this paper suggest that the price behavior in ASE does not follow the random walk model over time. However, this does not necessarily imply a violation of weak form efficiency (vice versa is not correct).
\end{abstract}

Keywords: Market efficiency, Runs test, Random Walk model, Amman Stock Exchange

\section{Introduction}

The theory of market efficiency involves defining an efficient market as one in which trading on available information fails to provide an abnormal profit. Three levels of market efficiency have been defined; firstly, the weak form of the efficient market hypothesis which claims that prices fully reflect the information implicit in the sequence of past prices. Secondly, the semi-strong form of the efficient market hypothesis which asserts that prices reflect not only past prices but all relevant information that is publicly available. Researchers have tested this by looking at specific items of news such as announcements of earnings and dividends, forecasts of company earrings, changes in accounting practices, and mergers. Thirdly, the strong form of the efficient market hypothesis which asserts information that is known to any participant is reflected in market prices; hence, prices reflect not just public information but all the information that can be acquired by painstaking fundamental analysis of the company and the economy. In such a case, prices would always be fair and no investor would be able to make consistently superior forecasts of stock prices. Most tests of this view have involved an analysis of the performance of professionally managed portfolios.

The efficient market hypothesis yields a variety of testable predictions about the behaviour of financial asset prices and returns. The following are examples of these predictions (Beechey, Gruen, and Vickery 2000):

- Asset prices move as random walks over time, which test the weak form level. Technical analysis should provide no useful information; also test the weak form level.

- New information is rapidly incorporated into asset prices, and currently available public information cannot help in achieving abnormal returns, which tests the semi-strong level by using the event study.

- Fund managers cannot outperform the market, testing the strong form level.

- The actual asset price at any point in time will be a good estimate of its fundamental value, testing also the strong form level.

In order to investigate whether asset prices move as random walk over time, the hypothesis that successive price changes are independent must be tested. Different approaches have been utilised in literature. One is an approach 
that relies primarily on common statistical tools, such as the runs test which determines whether successive price changes are independent, and consequently, whether the market is weak-form efficient. This approach has been used excessively and produced evidence of important independence in series of successive price changes in developed markets. The non-parametric runs test determines whether successive price changes are independent, but unlike its parametric equivalent serial correlation test, the runs test does not require returns to be normally distributed (Levene, 1952).

\subsection{Review of Empirical Studies}

This section presents a review of the empirical studies for runs test. It starts with studies conducted in developed financial markets and follows this with a review of studies conducted in emerging markets, then a review of studies conducted in the ASE.

\subsubsection{Developed Markets}

The early studies testing for weak form efficiency started on developed markets and applied runs tests. Generally, these studies supported the weak-form efficiency of the market, where it found an insignificant difference between the expected and observed number of runs, hence, the null hypothesis that the daily returns are random couldn't be rejected. Kendall (1953) stated that "an analysis of stock-exchange movements revealed little serial correlation within series and little lag correlation between series. Unless individual stocks behave differently from the average of similar stocks, there is no hope of being able to predict movements in the exchange for a week ahead without extraneous information". Similar conclusions have also been reached by Fama (1965). This study used the daily prices for the thirty stocks of Dow-Jones Industrial Average over the period 1957-1962 to test the empirical validity of the independent hypothesis of the random walk model. Serial correlation and runs tests (in addition to other technical tests) were applied to daily, four-day, nine-day, and sixteen-day price changes. The results showed little evidence, either of serial correlations or, from the various runs tests, of any large degree of dependence in price changes. Hence, dependency in price changes can not explain the departures from normality that has been observed in the empirical distribution of price changes. Cooper (1982) studied world stock markets using monthly, weekly and daily data for 36 countries. He examined the validity of the random walk hypothesis by employing correlation analysis, runs tests and spectral analysis. With respect to the USA and the UK, the evidence supported the random walk hypothesis.

In general, most empirical studies conducted in developed markets have tended to uphold weak form efficiency and thus no abnormal return would occur by using past prices.

\subsubsection{Emerging Markets}

Although it is generally believed that emerging markets are less efficient than developed markets, the research findings on emerging markets are actually quite mixed. There are different studies in favour of weak-form efficiency in developing markets which applied runs tests technique. Branes (1986) tested the applicability of the random walk hypothesis to the Kuala Lumpur Stock Exchange, using the traditional statistical techniques: serial correlation, runs, and spectral analysis. The Kuala Lumpur Stock Exchange exhibits a high degree of weak-form efficiency. Dickinson and Muragu (1994) used weekly prices over ten years of the 30 most actively traded equities on the Nairobi Stock Exchange. They failed to find evidence inconsistent with weak-form efficiency in the stock exchange by means of both runs tests and Q-test statistics, but suggested that a number of studies must be carried out on any market using a variety of methodologies to draw firm conclusions about weak-form efficiency.

Urrutia (1995) tests showed opposite results. He used variance-ratio tests and runs tests to investigate random walk and weak-form market efficiency in four Latin American emerging stock markets: Argentina, Brazil, Chile, and Mexico. Results from the variance-ratio estimates obtained, assuming homoskedasticity, reject the random walk hypothesis for the four Latin American markets. However, the runs tests indicate that the four Latin American markets are weak-form efficient. Urrutia suggested that investors might not be able to detect patterns in stock prices and develop trading strategies that would allow them to earn abnormal returns, as one interpretation for these results.

El-Erian and Kumar (1995) also found some departures from weak-form efficiency in Middle Eastern stock markets, but emphasise the serial dependence is sufficiently weak that it likely has little value in predicting future prices. Their finding is consistent with that of Butler and Malaikah (1992), who found statistically significant autocorrelation in the stock markets of Kuwait and Saudi Arabia. Nourrrendine Kababa (1998) has also examined the behavior of stock prices in the Saudi Financial Market, seeking evidence for weak-form efficiency, but found that the market is not weak-form efficient. Poshakwale (1996) investigated the weak form efficiency and the day of week effect in the Bombay Stock Exchange using runs test and serial correlation coefficient tests. The results of runs test and serial correlation coefficient tests indicate a nonrandom nature of the series and, therefore, violation of weak 
form efficiency in the BSE. The other null hypothesis that there is no difference between the returns achieved on different days of the week is also rejected as there is clear evidence that the average returns are different on each day of the week. Mobarek (2000) examined the weak-form efficiency in Dhaka Stock Exchange using the daily price indices of all the listed securities on the DSE for the period 1988 to 1997. The results of both non-parametric tests (Kolmogrov -Smirnov normality test and run test) and parametric tests ( Auto-correlation test, Auto-regression, ARIMA model ) provided evidence that the share return series do not follow the random walk model, and the significant autocorrelation co-efficient at different lags reject the null hypothesis of weak-form efficiency.

Moustafa (2004) examines the behavior of stock prices in the United Arab Emirates (UAE) stock market using daily prices of 43 stocks included in the UAE market index for the period October 2, 2001 to September 1, 2003. He finds that the returns of the 43 stocks do not follow normal distribution. However, the results of runs tests show that the returns of 40 stocks out of the 43 are random at $5 \%$ level of significance. Although the UAE stock market is newly developed and it is still very small, also suffering from infrequent trading, according to his results, the UAE is found to be weak-form efficient.

Pandey (2003) analysed the efficiency of the Indian stock markets by using three Indian stock indices to test the efficiency level in Indian stock market and the random walk nature of the stock market by using the runs test and the Auto Correlation Function ACF (K) for the period from January 1996 to June 2002. The study found that the series of stock indices in the Indian stock market biased the random time series and do not confirming the Random Walk Theory.

Sharma et al. (2009) examined the weak-form efficiency of eleven (11) securities listed on the BSE using weekly data from July 2007 to October 2007 by employing runs test and auto-correlation tests. The study concludes that the BSE is weak-form efficient and the stock prices are having very scrimpy effect on future prices which implies that an investor cannot reap out abnormal profits as the current share prices already reflect the effect of past share prices.

Pradhan et al. (2009) in their paper tried to examine the Efficient Market Hypothesis (EMH) in its weak - form by employing the unit root test on the sample of daily stock returns of National Stock Exchange (NSE) and Bombay Stock Exchange (BSE). The sample period lies between Jan.2007 to Jul.2009. The study reveals that Indian Stock market is not weak - form efficient.

Worthington and Higgs (2004) find that Germany and Netherlands are weak form efficient under both serial correlation and runs tests, while Ireland, Portugal and the United Kingdom are efficient under one test or the other. Thus, rests of the markets do not follow a random walk Tas and Dursonoglu (2005) have confirmed the inefficiency result for Turkey using daily stock returns of ISE 30 indices from the period 1995 to 2004. Dickey-Fuller unit root and runs tests were used in their studies and the results of both tests reject random walk hypothesis in ISE.

Akinkugbe (2005) finds stock markets in Botswana to be weak and semi-strong form efficient. His data includes 738 weekly observations for the period June 1989 to December 2003. Autocorrelation, and Augmented Dickey-Fuller and Phillip-Perron unit root tests were used to investigate the weak form of EMH in Botswana stock exchange. In his study, autocorrelation test show evidence of no serial correlation and the results of both unit root tests indicate a stationary process for stock returns, therefore implying weak-form efficiency.

Using the serial correlation, runs and unit root tests Abeysekera (2001) indicates that the Colombo Stock Exchange (CSE) in Sri Lanka is weak-form inefficient. His data include daily, weekly and monthly returns of the Sensitive Share Index (based on market prices of 24 blue-chip companies listed on the CSE) and a 40-security value weighted index for the period January 1991 to November 1996. The results of three tests consistently reject the random walk hypothesis.

(Abraham et al. 2002) they all use variance ratio tests and runs test on the financial data of different countries for testing random walk hypothesis and found week form efficient these markets are and follow a random walk.

Hassan et al. (2006) conduct a test of efficiency in seven European emerging stock markets. They use International Finance Corporation's weekly stock index data for the period December 1988 through August 2002. Several methods used in their studies including Ljung-Box Q-statistic, runs, and variance ratio tests. According to their results, except Greece, Slovakia, and Turkey, markets in Czech Republic, Hungary, Poland and Russia are found to be unpredictable.

Dragotă et al. (2009) analyze the returns of 18 stocks listed at the BSE first category and of the Romanian capital market indices.11 The stocks and indices are monitored from their listing (respectively the indexes construction) date to the end of 2006. Dragotă et al. (2009) focus on the weak form efficiency, according to which all of the past prices information is incorporated into the current price and, consequently, there could not be obtained systematic abnormal returns based on historical information on prices. The investigation on the weak form of the efficient 
market hypothesis is based on the following tests of the random walk hypothesis: the Cowels-Jones test, the runs test and the Multiple Variance Ratio - MVR - approach.

Filis (2006) tested the efficiency level of ASE by performing several tests for the period 2000-2002. These include unit roots (ADF) runs and GARCH effects tests. Furthermore he used the Wilcoxon Signed Rank test for the equality of implied versus historic volatility. He rejected the semi-strong form of efficiency as he found evidence of volatility clustering whereas he accepted the weak form as he found that the returns for this period followed a random walk.

Briefly, the previous studies cannot support or contradict the weak form efficiency in emerging markets. Much work must be conducted to investigate price dynamics in emerging markets. It is interesting to find if ASE is weak-form efficient and to what extent, and to explore the return generating process by using serial correlation and runs tests.

\subsubsection{ASE}

Few studies investigated the weak form efficiency of ASE by using the conventional tests. El-Erian and Kumar (1994) analyzed the development of equity markets in selected Middle Eastern countries, and evaluated their informational efficiency. The analysis focused on a sample of six countries consisting of: relatively active markets, (Jordan and Turkey), an established but less active market (Eygpt), and more recently established markets (Iran, Morocco, and Tunisia). A range of quantitative indicators, including market capitalization and concentration, price earnings ratios, price volatility, and the extent of correlation with industrial country markers, are applied. A quantitative analysis of the efficiency of selected markets in the region, and a comparison of the efficiency of these markets with a number of other emerging markets, are also undertaken. The results show that there are significant differences across these countries in the importance and characteristics of equity markets. For example, the study measured the volatility of the Jordanian and Turkish markets and compared it with other emerging and developed markets. The emerging markets have been found to be more volatile than the developed markets. Nevertheless, the Jordanian market exhibits the lowest volatility among the emerging markets. The paper also examined the degree to which emerging equity markets are efficient in pricing stocks, through assessing whether stock prices display any systematic patterns or whether they are indistinguishable from random walk. The empirical evidence is based on the serial correlation, for the first ten lags, and the non-parametric runs technique. Daily and weekly data were used. For the daily series for Jordan, the results indicate that the first order serial correlation (0.194) is highly significant, and hence, the random walk model does not hold. For the higher order coefficients, the $3^{\text {rd }}, 4^{\text {th }}$, and $6^{\text {th }}$ are significant. In the case of the weekly data, the pattern is different: the serial correlation coefficients are not statistically significant only for the $4^{\text {th }}$ lag and at the $10 \%$ level.

The runs test is performed by comparing the actual number of runs (defined as a sequence of price changes of the same sign preceded and followed by price changes of different signs) with the expected number of runs on the assumption that price changes are independent. If the observed runs are not significantly different from the expected number of runs, then the inference is that successive price changes are independent. The results of the runs analysis for both the daily and weekly data indicate that the null hypothesis of independence could be rejected at the $1 \%$ level.

Another study for Karemera, Ojah, and Cole (1999) reported different interesting results. They used the runs test and the single and multiple variance-ratio tests to examine the stochastic properties of local currency -and US dollarbased equity returns in 15 emerging capital markets. The results indicate that the majority of the emerging equity series analysed are consistent with the RWH and weak form efficient when both local currency-based data and exchange rate-adjusted data are used. The data comprises monthly national stock price indices expressed in both domestic (local) currency and US dollars from 1987:12 to 1997:5, and obtained from Morgan Stanley Capital Information (MSCI) files for emerging markets. The study also provides some descriptive statistics on returns of the stock indices.

According to Karemera, Ojah, and Cole (1999), and El-Erian and Kumar (1994) results, Jordan is found to have the lowest standard deviation (a measure of asset's risk) among the emerging markets covered in the study. However, according to the runs test statistics, the hypothesis of independence can not be rejected at the $5 \%$ level for the Jordanian equity return series, and also for most of the emerging markets covered in the study, for both US dollar-based data and local currency-based data. Hence, the Jordanian market and most of the emerging markets covered in the study are weak-form efficient.

Karemera, Ojah, and Cole present different possible reasons for the presence of a positive and/or negative serial correlation when a market is, at the same time, documented to be weak-form efficient. For example, infrequent or nonsynchronous trading patterns can yield a positively autocorrelated stock price series behaviour. When small-capitalized firms trade less frequently than large-capitalized firms, information is impounded first into 
large-capitalized firms' prices, and then small- capitalized firms', with a lag; and this lag induces a positive serial correlation in the index series that contain these distinct capitalized groups of stocks. Given the market concentration of the top large companies whose stocks dominate the emerging market indices, this explanation is not far-fetched. The effects of government interventions can also be another reason for the positive autocorrelation in emerging equity markets' series. Furthermore, they reported that RWH seems to be sensitive to the test observation intervals of the series, and the testing methodology used. On the other hand, the results of variance ratio tests suggest that the Jordanian market does not follow a random walk for either US dollar-based data or local currency-based data for all intervals, given that the observation intervals $\mathrm{q}=2,4,8,16$ months, with a base of one month, variance ratio estimates are computed for two-month, four-month, eight-month, and sixteen month observation intervals.

Omet (1990) examined the Jordanian market in its beginings, by using the daily prices for most active sixteen shares, and covered the period from $1^{\text {st }}$ Jan. 1979 to $31^{\text {st }}$ Dec. 1986. He applied the serial correlation model, runs analysis, distribution of runs by length, and filter technique. The price time series of each of the sixteen shares are used to calculate the sample correlation coefficients for daily changes in log prices for the first five lags. For the first lag, the coefficients for all shares are significant and range from +0.269 to -0.061 . For the other lags, the correlation coefficients are close to zero and most of them are statistically insignificant. Hence, results suggest that the price changes reflect some degree of significant positive dependency patterns. The runs test was performed for the sixteen shares for the 1-day and 2-day price changes. The number of actual runs for the 1-day price change was found to be less than the number of expected for all shares, thirteen of these differences are significant. However, regarding the 2-day price changes, fifteen shares were found to have actual runs less than expected, but these differences are not significant. Omet concluded that the 1-day price changes reflect positive dependency patterns, which is in agreement with the serial correlation model's results.

\subsection{Data and Descriptive Statistics}

\subsubsection{Data}

Data tested comprised of the daily prices of the five indices in ASE from $1^{\text {st }}$ January 2000 to $31^{\text {st }}$ December 2008 .

\subsubsection{Descriptive Statistics}

Summary statistics for the ASE indices are presented in Table 1.1. ( see appendix 1) The daily return for each index is calculated as: $\ln \left(p_{t}\right)-\ln \left(p_{t-1}\right)$ where $\ln \left(p_{t}\right)$ is the natural logarithm of the index at time (day) $t$. Dividends are assumed away (Campbell et al., 1997). Of the five indices, the bank index has the highest average return of 0.00035 over the time period 2000-2008, while the industry index has the lowest and the only negative mean daily average return of (-0.00014). In case of standard deviation of stock returns, the bank and industry sectors have the greater fluctuations. Whilst one of the basic assumptions of random walk model is that the distribution of the return series should be normal, it can be seen from Table 1.1 that the frequency distribution of the return series for each index is not normal. The normal distribution has a skewness coefficient of zero and a kurtosis coefficient of 3 . Skewness is a measure of symmetry, or more precisely, lack of symmetry. A distribution, or data set, is symmetric if it looks the same to the left as it does to the right of the centre point. The formula for the Skewness is:

$$
S=\frac{\frac{1}{T} \sum_{t=1}^{T}\left(y_{t}-\bar{y}\right)^{3}}{\sigma^{3}}
$$

Where $\bar{y}$ is the mean, $\sigma$ is the standard deviation, and $T$ is the number of observations.

Negative values for skewness indicate data that are skewed left, and positive values for skewness indicate data that are skewed right. By skewed left, we mean that the left tail is heavier than the right tail. Similarly, skewed right means that the right tail is heavier than the left tail. Some measurements have a lower bound and are skewed right. For example, in reliability studies, failure times cannot be negative.

Regarding ASE indices, the skewness coefficient is positive for all indices. These lie in the opposite direction to that commonly manifested by most stock markets (see, for example, Harvey and Siddique, 1999; Peiró, 1999; and Premaratne and Bera, 2001).

Kurtosis is a measure of whether the data is peaked or flat, relative to a normal distribution. That is, data sets with high kurtosis tend to have a distinct peak near the mean, decline rather rapidly, and have heavy tails. Data sets with low kurtosis tend to have a flat top near the mean rather than a sharp peak. A uniform distribution would be the extreme case. The formula for Kurtosis is: 


$$
K=\frac{\frac{1}{T} \sum_{t=1}^{T}\left(y_{t}-\bar{y}\right)^{4}}{\sigma^{4}}
$$

where $\bar{y}$ is the mean, $\sigma$ is the standard deviation, and $T$ is the number of observations.

The kurtosis of a normal distribution is 3 . If the distribution has thicker tails than does the normal distribution, its kurtosis will exceed three. A positive kurtosis indicates a peaked distribution, while a negative kurtosis indicates a flat distribution.

The kurtosis coefficient is higher than 3 for all indices, indicating a leptokurtic distribution. A kurtosis higher than 3 indicates a leptokurtic distribution, while one lower than 3 indicates a playkurtic distribution (Parkinson, 1987). Hence, skewness and kurtosis values for the ASE indices return series deviated from the normal distribution both on skewness and kurtosis values and at 1\% significant level, indicating that the distribution of indices return series are not normal. In light of the previous results, and to assess the extent of non-normality in the distributions of the indices return series, the Jarque-Bera statistic is used to test whether each series is normally distributed. The test statistic measures the difference of the skewness and kurtosis of the series with those from a normal distribution.

Under the null hypothesis of a normal distribution, the Jarque-Bera statistic is distributed as $\chi^{2}$ with 2 degrees of freedom. The reported probability is the probability that a Jarque-Bera statistic exceeds (in absolute value) the observed value under the null hypothesis; a small probability value leads to the rejection of the null hypothesis of a normal distribution. The formula for Jarque-Bera is:

$$
J B=\frac{T-k}{6}\left[S^{2}+\frac{1}{4}(K-3)^{2}\right]
$$

where $T$ is the number of observations, $k$ is zero for an ordinary series and the number of regressors when examining residuals to regression equation, $S$ is skewness and $K$ is kurtosis (Bera, 1981). As shown in Table 1.1, the probabilities, for the $J B$ test, for the indices return series are all less than 0.0001 , which is statistically significant at $1 \%$ level and confirms that the distribution of the daily price indices of the ASE is not normal.

This result supports earlier findings that the emerging market returns are not normally distributed (Harvey, 1995). Bekaert and Harvey (2002) reported the skewness and excess kurtosis of twenty emerging markets, including Jordan, with the longest history in the EMDB, the IFC composite portfolio and the MSCI world market portfolio (pre-1990 and post-1990).

It is noticeable that the return series of the ASE has a positive skewness, which contradicts the IFC composite portfolio and the MSCI world market portfolio as well as most of other emerging markets. The average monthly excess of kurtosis is consistent with other emerging markets and very close to the world index.

\section{Non-Parametric Runs Test}

The runs test is an approach to determine whether successive price changes are independent; the normality assumption of distribution is ignored by this test. The null hypothesis for the runs test is that the observed series is a random series. A run is defined by Siegel (Siegel, 1956) as: "a succession of identical symbols which are followed or preceded by different symbols or no symbol at all". For the purpose of this test, runs up and down, distribution of runs by length, and runs above and below are applied.

\subsection{Runs Up and Down}

A run is counted every time the price series changes its sign. There are three possible changes: positive $(+)$, negative $(-)$, and zero changes (0). A run of length $i$ is defined as $i$ consecutive + or - or 0 . In other words, a plus run of length $i$ is a sequence of $i$ consecutive positive price changes preceded and followed by either negative or zero changes. For example, the sequence of daily prices of $(166.05,166.38,165.78,165.20,164.57,164.01,163.97$, $164.03,164.86,164.86,164.28,163.79,164.47,164.54)$ has 6 runs $(+,-,+, 0,-,+)$ with lengths of $(1,6,2,1,1,2)$ respectively.

This test examines if the direction of one observation influences the direction taken in later observations. The run's test compares the observed number of runs with the expected number of runs, which are computed under the assumption that prices fluctuate randomly and independently (Fama, 1965):

$$
\text { Expected Runs }=\left[N(N+1)-\sum_{i=1}^{3} n_{i}^{2}\right] / N
$$

Where $\mathrm{N}$ is the total number of return observations, and $\mathrm{n}_{\mathrm{i}}$ is the number of price changes of each sign. 
The standard error of the series $(\sigma)$ of runs can be shown to be (Fama, 1965):

$$
\text { Standard Error }=\left(\frac{\sum_{i=1}^{3} n_{i}^{2}\left[\sum_{i=1}^{3} n_{i}^{2}+N(N+1)\right]-2 N \sum_{i=1}^{3} n_{i}^{3}-N^{3}}{N^{2}(N-1)}\right)^{1 / 2}
$$

The difference between the actual number of runs and the expected number of runs is examined for significance. Thus the difference between the actual number of runs, $R$, and the expected number, $m$, can be expressed by means of the usual standardized variable,

$$
Z=\frac{\left(R+\frac{1}{2}\right)-m}{\sigma_{m}}
$$

where the half in the numerator is a discontinuity adjustment. For large samples, $Z$ will be approximately normal with a mean (0) and a variance (1). When the difference is found to be significant, this means that daily returns are not random and that there is an opportunity to make abnormal returns. If the actual number of runs are significantly less than the expected value, this indicates the market's overreaction to information, while a higher number of runs reflects a lagged response to information (Poshokwale, 1996).

\subsection{Empirical Results}

The non-parametric runs test is considered more appropriate than a parametric serial correlation test as the returns data does not conform to the normal distribution (Jarque-Bera test statistic is reported in Table 1.1). The standard normal Z-statistic can be used to test whether the actual number of runs is consistent with the independence hypothesis. If the $\mathrm{Z}$ value is greater than or equal to \pm 1.96 , the null hypothesis at the $5 \%$ level of significance is rejected (Sharma and Kennedy, 1977).

When the actual number of runs exceeds (falls below) expected runs, a positive (negative) $\mathrm{Z}$ value is obtained. A positive (negative) $Z$ value indicates negative (positive) serial correlation in the return series. As can be seen from Table 1.2, the $\mathrm{Z}$ statistics of the daily market return is greater than \pm 2.64 and negative for all indices. This means that the observed number of runs is significantly fewer than the expected number of runs at the $1 \%$ level of significance. Therefore, the null hypothesis that the return series of the indices follow a random walk can be rejected for all series.

Even though the empirical results rejected the random walk, runs tests are not considered a sophisticated method for identifying movements, since the termination of the movement is simply predicted when the price level has temporarily changed direction, regardless of the size of the price change that caused the change in sign. It is also consistent with other emerging market studies. For example, Poshokwale (1996) reported that the daily return series in the Indian, Philippine, Malaysian, and Thailand market produced an actual number of runs significantly lower than the expected number of runs. El-Erian and Kumar (1994) and Omet (1990) reported similar results for the Jordanian market, even though the study periods were different.

The next step is to analyze the difference between the actual and expected number of runs using the distribution of runs by length (number of days), in other words, by examining the differences-in length-between the actual and expected number of each sign.

\subsubsection{Distribution of Runs by Length}

When the differences between the actual and expected number of runs is significant, the distribution of runs by length analysis provides a more detailed description and answers the following question: given the total actual number of runs of each sign, how would we expect the totals to be distributed among runs of different lengths, and what is the actual distribution? In other words, if the signs of the price changes are generated by an independent process with their respective probabilities of $\mathrm{P}(+), \mathrm{P}(-)$ and $\mathrm{P}(0)$, we are required to examine the differences (in length) between the actual and expected runs of each sign (TSP software is used to perform this test as shown in Appendix 2).

Depending on the actual number of positive price changes $(\mathrm{NP}(+))$, negative price changes $(\mathrm{NP}(-))$, and zero price changes $(\mathrm{NP}(0))$, the probability of positive price change $[\mathrm{P}(+)]$ to occur would be: (Fama, 1965)

$$
P(+)=N P(+) /[N P(+)+N P(-)+(N P(0)]
$$

and P (-), P (0) would be

$$
P(-)=N P(-) /[N P(+)+N P(-)+(N P(0)]
$$




$$
P(0)=N P(0) /[N P(+)+N P(-)+(N P(0)]
$$

The expected proportion of positive runs of length $\mathrm{i}$ (where $\mathrm{i}=1,2,3, \ldots, \alpha)$ would be $P(+)^{i-1}[1-P(+)]$ (Fama, 1965). In other words, given that a positive run has occurred, this proportion is equivalent to the conditional probability of positive runs of length i( the sum of the conditional probabilities for positive runs of all length will be one). Similarly, this is applied for negative and zero runs to get the expected distributions by length of the total actual number of runs of each sign: $P(-)^{i-1}[1-P(-)]$ and $P(0)^{i-1}[1-P(0)]$ respectively. The expected distributions, by length, of the total actual number of runs of each sign could be calculated by using (1.10), (1.11), and (1.12). The expected numbers of positive, negative, and zero runs of length $i$ (where $i=1,2,3, \ldots, \alpha)$ are calculated as: (Fama, 1965)

$$
\begin{gathered}
\bar{R}_{i}(+)=R(+) P(+)^{i-1}[1-P(+)] \\
\bar{R}_{i}(-)=R(-) P(-)^{i-1}[1-P(-)] \\
\bar{R}_{i}(0)=R(0) P(0)^{i-1}[1-P(0)]
\end{gathered}
$$

where $\bar{R}_{i}(+), \bar{R}_{i}(-)$ and $\bar{R}_{i}(0)$ are the expected numbers of positive, negative and zero runs of length $\mathrm{i}$ and $R(+)$, $R(-)$ and $R(0)$ are the total actual numbers of positive, negative and zero runs.

\subsubsection{Empirical Results}

Table 1.3 reports, for each type of run, the probability of a run of each length, the expected number of runs of each length, and the actual number of runs of each length for the five indices. It is noticeable that all indices produced similar results, and that there are very few long runs. The most interesting point is that, for the runs of length 1 day, the actual number of runs is predominantly less than the expected number of runs. However, for runs of length 4 or more days, the actual number is mostly greater than the expected number. These results support the Omet (1990) results and previous runs test analyses, and suggest that the indices price series could not be characterised as random walk. The next chapter will investigate whether these short term trends of similar price changes could be utilized by a trader to increase the expected profit, by applying the filter Runs Above and Below

A run is counted every time the price series rises above or falls below a cut point measure (which may be the mean, median, mode, or any other chosen value). Each price observation is classified with either a + or - to indicate whether the price is above or below the cut point (theoretically, an observation could equal the cut point, and in this case according to SPSS package, the observation is classified as +). After classifying the observations, they are investigated for "runs". Unlike the runs before, the runs sought this time are of consecutive numbers that share the property of being above or below the cut point. Then, the number of numbers above the cut point is counted, as well as the number of numbers below the cut point. Lastly, the total number of runs is counted. The computation of the cutting point, number of runs, and significance level, are as follows: (according to the SPSS guide as this package is the used to perform the test).

\subsection{Computation of Cutting Point}

The cutting point which is used to dichotomize the data can be specified as a particular number, or the value of a statistic which is to be calculated. The possible statistics are:

$$
\begin{gathered}
\text { Mean }=\sum_{i=1}^{N} X_{i} / N \\
\text { Median }= \begin{cases}\left(X_{(N / 2+1)}+X_{(N / 2)}\right) / 2 & \text { if } N \text { is even } \\
X_{((N+1) / 2)} & \text { if } N \text { is odd }\end{cases}
\end{gathered}
$$

where the data are sorted in an ascending order from $X_{(1)}$, the smallest, to $X_{(N)}$, the largest. The mode is the most frequently occurring value. If there are multiple modes, the one largest in value is selected.

\subsubsection{Numbers of Runs:}

For each observation, the difference between the observation and the cut point is computed,

$$
D_{t}=X_{t}-\text { Cutpoint }
$$

If $D_{t} \geq 0$, the difference is considered positive. Otherwise it is negative. The number of times the sign changes, that

is, $D_{t} \geq 0$ and $D_{t+1}<0$, or $D_{t}<0$ and $D_{t+1} \geq 0$, as well as the number of positive $\left(n_{p}\right)$ and negative $\left(n_{a}\right)$ signs, are determined. The number of runs $(R)$ is the number of sign changes plus one. 


\subsubsection{Significance Level:}

The sampling distribution of the number of runs $(R)$ is approximately normal with

$$
\begin{gathered}
\mu_{r}=\frac{2 n_{p} n_{a}}{n_{p}+n_{a}}+1 \\
\sigma_{r}=\sqrt{\frac{2 n_{p} n_{a}\left(2 n_{p} n_{a}-n_{a}-n_{p}\right)}{\left(n_{p}+n_{a}\right)^{2}\left(n_{p}+n_{a}-1\right)}}
\end{gathered}
$$

The two-sided significance level is based on

$$
z=\frac{R-\mu_{r}}{\sigma_{r}}
$$

\subsection{Empirical Results}

The observed mean, median, and mode are used as cut points. Cases with values less than the cut point are assigned to one group, and cases with values greater than or equal to the cut point are assigned to another group. One test is performed for each cut point chosen.

Tables 1.4, 1.5, and 1.6 (see appendix 1) present the results for the five series of indices daily prices for the period from $1^{\text {st }}$ January 2000 to $31^{\text {st }}$ December 2008, considering the mean, median, and mode of the daily prices as cut points.

The "Test Value" in each output table corresponds to the statistic value used as the cut point. Referring to the $\mathrm{Z}$ statistics reported by the above tables, all the tests show that the null hypothesis of randomness can not be rejected. Hence, runs tests using all three measures of central tendency (median, mean, and mode) are consistent with previous results demonstrated in this chapter. On the other hand, these results contradict the findings of Karemera, Ojah, and Cole (1999); they reported that the hypothesis of independence can not be rejected at the $5 \%$ level for the Jordanian equity return series. However, the other tests used in their study, simple and multiple variance ratio tests, suggest that the Jordanian market is not weak-form efficient. In The study of Karemera, Ojah, and Cole (1999) consisted of 114 monthly observations of the returns covering the period from 1987:12 to 1997:5. The returns series is used to perform the runs test

\subsection{Conclusion}

Empirical literature suggests that the price behaviour in developed markets can be characterized as random walk. However, it is still controversial in the case of developing countries. The empirical results obtained in this chapter for the ASE suggests that it is not weak-form efficient. The ASE reflects a high degree of positive temporal dependency patterns, violating the assumption of random walk model.

However, this does not necessarily imply a violation of weak form efficiency. As Ko and Lee (1991) state that if the random walk hypothesis holds, the weak-form of the efficient market hypothesis must hold, but not vice versa. Thus, evidence supporting the random walk model is evidence of market efficiency. But violation of the random walk model need not be evidence of market inefficiency in the weak form.

\section{References}

Abraham, A., Seyyed, F. J., \& Alsakran, S. A. (2002). Testing the random behavior and efficiency of the Gulf stock markets, The Financial Review, 37(3), 469-480. http://dx.doi.org/10.1111/0732-8516.00008

Beechey, M., Gruen, D., \& Vickery, J. (2000). The Efficient Market Hypothesis: A Survey. Research Discussion Paper, Economic Research Department, Reserve Bank of Australia.

Branes, P. (1986). Thin Trading and Stock Market Efficiency: A Case of the Kuala Lumpur Stock Exchange. Journal of Business Finance and Accounting, 13, 609-617. http://dx.doi.org/10.1111/j.1468-5957.1986.tb00522.x

Butler, K. C., \& Malaikah, S. J. (1992). Efficiency and Inefficiency In Thinly Traded Stock Markets: Kuwait and Saudi Arabia. Journal of Banking and Finance, 16, 197-210. http://dx.doi.org/10.1016/0378-4266(92)90085-E

Chakraborty, M. (2006). Market Efficiency for the Pakistan Stock Market. South Asia Economic Journal, 7(1), 67-81. http://dx.doi.org/10.1177/139156140500700104

Cooper, J., (1982). World Stock Market: Some Random Walk Test. Applied Economics, 14, 512-531. http://dx.doi.org/10.1080/00036848200000046

Dickinson, J., \& Muragu, K. (1994). Market Efficiency in Developing Countries: A Case Study of the Nairobi Stock 
Exchange. Journal of Business Finance and Accounting, 21, 133-149, http://dx.doi.org/10.1111/j.1468-5957.1994.tb00309.x

Dragotă, V., Stoian, A., Pele, D, T., Mitrică, E., \& Bensafta, M. (2009). The Development of the Romanian Capital Market: Evidences on Information Efficiency. Romanian Journal of Economic Forecasting, 10, 147-160.

El-Erian, M., \& Kumar, M. (1994). Emerging Equity Markets in Middle Eastern Countries. International Monetary Fund, Middle Eastern \& Research Departments. Working Paper, WP/94/103.

Fama, E. (1965). The Behavior of Stock-Market Prices. The Journal of Business, 38, 34-105. http://dx.doi.org/10.1086/294743

Filis, G. (2006). Testing for Market Efficiency in Emerging Markets: Evidence from the Athens Stock Exchange. Journal of Emerging Market Finance, 5, 121-133. http://dx.doi.org/10.1177/097265270600500201

Harvey, C., \& Siddique, A. (1999). Autoregressive Conditional Skewness. Journal of Financial and Quantitative Analysis, 34, 465-487. http://dx.doi.org/10.2307/2676230

Karemara, D., Ojah, K., \& Cole, J. (1999). Random Walks and Market Efficiency Tests: Evidence from Emerging Equity Markets. Review of Quantitative Finance and Accounting, 13, 171-188. http://dx.doi.org/10.1023/A:1008399910942

Kendall, M., (1953). The Analysis of Economic Time-Series, Part 1, Prices. The Journal of Royal Statistical Society, 116, 11-25. http://dx.doi.org/10.2307/2980947

Ko K.-S., \& Lee S.-B., (1991). A Comparative Analysis of the Daily Behavior of Stock Returns: Japan, The US \& the Asian NICs. Journal of Business Finance and Accounting, 18, 219-34. http://dx.doi.org/10.1111/j.1468-5957.1991.tb00590.x

Levene, H. (1952). On the power function of tests of randomness based on runs up and down. Annals of Mathematical Statistics, 23, 34-56. http://dx.doi.org/10.1214/aoms/1177729484

Mobarek, A., \& Keasey, K. (2000). Weak-form Market Efficiency of an Emerging Market: Evidence from Dhaka Stock Market of Bangladesh. Working Paper, Center for Development Studies, Bath University.

Moustafa, M. A. (2004). Testing the Weak-Form Efficiency of the United Arab Emirates Stock Market. International Journal of Business, 29(3), 310-325.

Nourredine, K. (1998). Behavior of Stock Prices in the Saudi Arabian Financial Market: Empirical Research Findings. Journal of Financial Management and Analysis, 11, 48-55.

Omet, G., Khasawneh, M., \& Khasawneh, J. (2002). Efficiency Tests and Volatility Effects: Evidence from the Jordanian Stock Market. Applied Economic Letters, 9, 817-821. http://dx.doi.org/10.1080/13504850210161931

Pandey A. (2003). Efficiency of Indian Stock Market. Time Series Course.

Peiró, A. (1999). Skewness in Financial Returns. Journal of Banking and Finance, 23, 847-862. http://dx.doi.org/10.1016/S0378-4266(98)00119-8

Poshakwale, S., (1996). Evidence on the Weak -Form Efficiency and the Day of the Week Effect in the Indian Stock Market. Finance India, 10, 605-616.

Pradhan, B. B., Das, K. B., \& Mishra, P. K. (2009). Empirical Evidence on Indian Stock Market Efficiency in Context of the Global Financial Crisis. Global J. Finance Manage, 1(2), 149-157.

Premaratne, G., \& Bera, A. (2001). Modelling Asymmetry and Excess Kurtosis in Stock Return Data. Working Paper, Department of Economics, University of Illinois.

Sharma, J. L., \& Robert, E. K. (1977). A Comparative analysis of stock price behavior on the Bombay, London and New York Stock Exchanges. Journal of Financial and Quantitative Analysis, 12(3), 391-413. http://dx.doi.org/10.2307/2330542

Sharma, G. D., \& Mahendru, M. (2009). Efficiency Hypothesis of the Stock Markets: A Case of Indian Securities. International Journal of Business and Management, 4(3),136-144.

Siegel, S. (1956). Non-parametric Statistics for Behavioral Sciences. New York, McGraw- Hill

Tas, O., \& Dursonoglu, S. (2005). Testing random walk hypothesis for Istanbul Stock Exchange. International Trade and Finance Association Conference Papers. [E-document] [Retrieved March 23, 2006] From: http://services.bepress.com/otfa/15th/art38

Urrutia, J. (1995). Tests of Random Walk and Market Efficiency. Journal of Financial Research, 18, 299-309. 
Table 1. Descriptive Statistics of Daily Indices Return

\begin{tabular}{|c|c|c|c|c|c|}
\hline & GENERAL & BANKS & INSURANCE & INDUSTRY & SERVICES \\
\hline Mean & 0.000154 & 0.000352 & 0.000148 & -0.000139 & 0.000008 \\
\hline Median & -0.000309 & -0.000254 & 0.000000 & -0.000564 & -0.000274 \\
\hline Maximum & 0.047449 & 0.048855 & 0.039177 & 0.047816 & 0.044548 \\
\hline Minimum & -0.043102 & -0.048470 & -0.045597 & -0.045998 & -0.044349 \\
\hline Std. Dev. & 0.006831 & 0.008228 & 0.005949 & 0.008348 & 0.008101 \\
\hline Skewness $^{\mathrm{a}}(\mathrm{S})$ & 0.422 & 0.676 & 0.408 & 0.334 & 0.324 \\
\hline t-statistics $^{\mathrm{b}}$ & 8.344 & 13.371 & 8.075 & 6.612 & 6.417 \\
\hline Kurtosis $^{\mathrm{c}}(\mathrm{K})$ & 8.778 & 8.613 & 14.358 & 7.905 & 7.256 \\
\hline t-statistics $^{\mathrm{d}}$ & 57.116 & 55.491 & 112.271 & 48.486 & 42.073 \\
\hline Jarque-Bera (JB) & 3331.90 & 3258.12 & 12670.03 & 2394.63 & 1811.33 \\
\hline Probability & 0.000000 & 0.000000 & 0.000000 & 0.000000 & 0.000000 \\
\hline Observations & 2345 & 2345 & 2345 & 2345 & 2345 \\
\hline
\end{tabular}

${ }^{a}$ For normal distribution the value of skewness is zero

${ }^{\mathrm{b}}$ The $t$-values indicate that the values of the skewness coefficient are statistically different than zero at $1 \%$ level of significance. The $t$-statistic is calculated as $\mathrm{S} /(\operatorname{sqr}(6 / 2345))$.

${ }^{\mathrm{c}}$ For normal distribution the value of Kurtosis is three.

${ }^{\mathrm{d}}$ The $t$-value indicates that the values of the Kurtosis coefficient are statistically different than three at $1 \%$ level of significance. The $t$-statistic is calculated as (K-3)/(squr(24/2345)). 
Table 1. Distribution of Runs by Length for the Actual and Expected Runs of Each Sign

\begin{tabular}{|c|c|c|c|c|c|c|c|c|c|c|c|}
\hline \multicolumn{12}{|c|}{ General Index } \\
\hline & \multicolumn{2}{|c|}{ (+)ve Runs } & \multirow[b]{2}{*}{ Actual } & \multirow[b]{2}{*}{ Length } & \multicolumn{2}{|c|}{ (-)ve Runs } & \multirow[b]{2}{*}{ Actual } & \multirow[b]{2}{*}{ Length } & \multicolumn{2}{|c|}{ (0) Runs } & \multirow[b]{2}{*}{ Actual } \\
\hline Length & Proba. & Expected & & & Proba. & Expected & & & Proba. & Expected & \\
\hline 1 & 0.503 & 193.5 & 168 & 1 & 0.501 & 193.5 & 139 & 1 & 0.997 & 2.0 & 2 \\
\hline 2 & 0.250 & 96.5 & 80 & 2 & 0.250 & 96.5 & 101 & 2 & 0.003 & 0.0 & 0 \\
\hline 3 & 0.125 & 48.1 & 56 & 3 & 0.125 & 48.1 & 41 & 3 & 0.000 & 0.0 & 0 \\
\hline 4 & 0.062 & 24.0 & 34 & 4 & 0.062 & 24.0 & 42 & 4 & 0.000 & 0.0 & 0 \\
\hline 5 & 0.031 & 12.0 & 18 & 5 & 0.031 & 12.0 & 21 & 5 & 0.000 & 0.0 & 0 \\
\hline 6 & 0.015 & 6.0 & 12 & 6 & 0.015 & 6.0 & 16 & 6 & 0.000 & 0.0 & 0 \\
\hline 7 & 0.008 & 3.0 & 7 & 7 & 0.008 & 3.0 & 13 & 7 & 0.000 & 0.0 & 0 \\
\hline 8 & 0.004 & 1.5 & 4 & 8 & 0.004 & 1.5 & 4 & 8 & 0.000 & 0.0 & 0 \\
\hline Other & 0.002 & 0.7 & 7 & Other & 0.002 & 0.7 & 9 & Other & 0.000 & 0.0 & 0 \\
\hline Total & 0.998 & 385.3 & 386 & Total & 0.998 & 385.3 & 386 & Total & 1.000 & 2.0 & 2 \\
\hline \multicolumn{12}{|c|}{ Bank Index } \\
\hline & \multicolumn{2}{|c|}{ (+)ve Runs } & & & \multicolumn{2}{|c|}{ (-)ve Runs } & & & \multicolumn{2}{|c|}{ (0) Runs } & \\
\hline Length & Proba. & Expected & Actual & Length & Proba. & Expected & Actual & Length & Proba. & Expected & Actual \\
\hline 1 & 0.504 & 205.7 & 194 & 1 & 0.503 & 205.7 & 163 & 1 & 0.993 & 6.0 & 6 \\
\hline 2 & 0.250 & 102.0 & 75 & 2 & 0.250 & 102.2 & 91 & 2 & 0.007 & 0.0 & 0 \\
\hline 3 & 0.124 & 50.6 & 57 & 3 & 0.124 & 50.8 & 64 & 3 & 0.000 & 0.0 & 0 \\
\hline 4 & 0.061 & 25.1 & 44 & 4 & 0.062 & 25.3 & 27 & 4 & 0.000 & 0.0 & 0 \\
\hline 5 & 0.030 & 12.4 & 17 & 5 & 0.031 & 12.5 & 25 & 5 & 0.000 & 0.0 & 0 \\
\hline 6 & 0.015 & 6.2 & 8 & 6 & 0.015 & 6.2 & 17 & 6 & 0.000 & 0.0 & 0 \\
\hline 7 & 0.007 & 3.1 & 6 & 7 & 0.008 & 3.1 & 8 & 7 & 0.000 & 0.0 & 0 \\
\hline 8 & 0.004 & 1.5 & 3 & 8 & 0.004 & 1.5 & 8 & 8 & 0.000 & 0.0 & 0 \\
\hline Other & 0.002 & 0.8 & 4 & Other & 0.002 & 0.8 & 6 & Other & 0.000 & 0.0 & 0 \\
\hline Total & 0.998 & 407.3 & 408 & Total & 0.998 & 408.2 & 409 & Total & 1.000 & 6.0 & 6 \\
\hline \multicolumn{12}{|c|}{ Industry Index } \\
\hline & \multicolumn{2}{|c|}{ (+)ve Runs } & & & \multicolumn{2}{|c|}{ (-)ve Runs } & & & \multicolumn{2}{|c|}{ (0) Runs } & \\
\hline Length & Proba. & Expected & Actual & Length & Proba. & Expected & Actual & Length & Proba. & Expected & Actual \\
\hline 1 & 0.503 & 194.2 & 167 & 1 & 0.501 & 194.2 & 141 & 1 & 0.996 & 3.0 & 3 \\
\hline 2 & 0.250 & 96.5 & 85 & 2 & 0.250 & 97.0 & 93 & 2 & 0.004 & 0.0 & 0 \\
\hline 3 & 0.124 & 47.9 & 57 & 3 & 0.125 & 48.4 & 50 & 3 & 0.000 & 0.0 & 0 \\
\hline 4 & 0.062 & 23.8 & 33 & 4 & 0.062 & 24.2 & 41 & 4 & 0.000 & 0.0 & 0 \\
\hline 5 & 0.031 & 11.8 & 15 & 5 & 0.031 & 12.1 & 19 & 5 & 0.000 & 0.0 & 0 \\
\hline 6 & 0.015 & 5.9 & 10 & 6 & 0.016 & 6.0 & 18 & 6 & 0.000 & 0.0 & 0 \\
\hline 7 & 0.008 & 2.9 & 10 & 7 & 0.008 & 3.0 & 11 & 7 & 0.000 & 0.0 & 0 \\
\hline 8 & 0.004 & 1.5 & 3 & 8 & 0.004 & 1.5 & 5 & 8 & 0.000 & 0.0 & 0 \\
\hline Other & 0.002 & 0.7 & 6 & Other & 0.002 & 0.8 & 10 & Other & 0.000 & 0.0 & 0 \\
\hline Total & 0.998 & 385.3 & 386 & Total & 0.998 & 387.3 & 388 & Total & 1.000 & 3.0 & 3 \\
\hline & & & & & Insur & nce Index & & & & & \\
\hline & $(+)$ & e Runs & & & $(-)$ & Runs & & & (0) & Runs & \\
\hline Length & Proba. & Expected & Actual & Length & Proba. & Expected & Actual & Length & Proba. & Expected & Actual \\
\hline 1 & 0.638 & 253.3 & 243 & 1 & 0.607 & 261.7 & 232 & 1 & 0.755 & 203.0 & 161 \\
\hline 2 & 0.231 & 91.7 & 85 & 2 & 0.239 & 102.8 & 96 & 2 & 0.185 & 49.8 & 66 \\
\hline 3 & 0.084 & 33.2 & 34 & 3 & 0.094 & 40.4 & 62 & 3 & 0.045 & 12.2 & 18 \\
\hline 4 & 0.030 & 12.0 & 10 & 4 & 0.037 & 15.9 & 20 & 4 & 0.011 & 3.0 & 12 \\
\hline 5 & 0.011 & 4.3 & 12 & 5 & 0.014 & 6.2 & 11 & 5 & 0.003 & 0.7 & 5 \\
\hline 6 & 0.004 & 1.6 & 8 & 6 & 0.006 & 2.4 & 4 & 6 & 0.001 & 0.2 & 4 \\
\hline 7 & 0.001 & 0.6 & 1 & 7 & 0.002 & 1.0 & 2 & 7 & 0.000 & 0.0 & 3 \\
\hline 8 & 0.001 & 0.2 & 2 & 8 & 0.001 & 0.4 & 0 & 8 & 0.000 & 0.0 & 0 \\
\hline Other & 0.000 & 0.1 & 2 & Other & 0.000 & 0.1 & 4 & Other & 0.000 & 0.0 & 0 \\
\hline Total & 1.000 & 397.0 & 397 & Total & 1.000 & 430.9 & 431 & Total & 1.000 & 269.0 & 269 \\
\hline
\end{tabular}




\begin{tabular}{|c|c|c|c|c|c|c|c|c|c|c|c|}
\hline \multicolumn{12}{|c|}{ Service Index } \\
\hline & \multicolumn{2}{|c|}{ (+)ve Runs } & \multirow[b]{2}{*}{ Actual } & \multirow[b]{2}{*}{ Length } & \multicolumn{2}{|c|}{ (-)ve Runs } & \multirow[b]{2}{*}{ Actual } & \multirow[b]{2}{*}{ Length } & \multicolumn{2}{|c|}{ (0) Runs } & \multirow[b]{2}{*}{ Actual } \\
\hline Length & Proba. & Expected & & & Proba. & Expected & & & Proba. & Expected & \\
\hline 1 & 0.510 & 215.2 & 216 & 1 & 0.504 & 215.2 & 167 & 1 & 0.986 & 11.8 & 12 \\
\hline 2 & 0.250 & 105.5 & 85 & 2 & 0.250 & 106.7 & 121 & 2 & 0.014 & 0.2 & 0 \\
\hline 3 & 0.122 & 51.7 & 50 & 3 & 0.124 & 52.9 & 50 & 3 & 0.000 & 0.0 & 0 \\
\hline 4 & 0.060 & 25.3 & 27 & 4 & 0.061 & 26.3 & 28 & 4 & 0.000 & 0.0 & 0 \\
\hline 5 & 0.029 & 12.4 & 14 & 5 & 0.030 & 13.0 & 27 & 5 & 0.000 & 0.0 & 0 \\
\hline 6 & 0.014 & 6.1 & 16 & 6 & 0.015 & 6.5 & 13 & 6 & 0.000 & 0.0 & 0 \\
\hline 7 & 0.007 & 3.0 & 6 & 7 & 0.007 & 3.2 & 9 & 7 & 0.000 & 0.0 & 0 \\
\hline 8 & 0.003 & 1.5 & 2 & 8 & 0.004 & 1.6 & 6 & 8 & 0.000 & 0.0 & 0 \\
\hline Other & 0.002 & 0.7 & 6 & Other & 0.002 & 0.8 & 6 & Other & 0.000 & 0.0 & 0 \\
\hline Total & 0.998 & 421.3 & 422 & Total & 0.998 & 426.2 & 427 & Total & 1.000 & 12.0 & 12 \\
\hline
\end{tabular}

Table 3. The Results for the Runs Up and Down Test

** Significant at $1 \%$ level

\begin{tabular}{|c|c|c|c|c|}
\hline Index & Actual Runs & Expected Runs & Standard Error & Z-statistic \\
\hline General & 929 & 1171.9 & 24.10 & $(-10.09)^{* *}$ \\
\hline Bank & 990 & 1175.1 & 24.07 & $(-7.71)^{* *}$ \\
\hline Industry & 942 & 1168.3 & 24.00 & $(-9.45)^{* *}$ \\
\hline Insurance & 1294 & 1540.6 & 22.72 & $(-10.88)^{* *}$ \\
\hline Service & 1042 & 1192.2 & 23.95 & $(-6.29)^{* *}$ \\
\hline
\end{tabular}

Table 4. Runs Above and Below the Median Test

\begin{tabular}{|c|c|c|c|c|c|}
\hline & General & Banks & Insurance & Industry & Services \\
\hline Test Value & 152.8 & 190.4 & 124.6 & 115.9 & 114.0 \\
\hline Cases < Test Value & 1172 & 1172 & 1171 & 1172 & 1172 \\
\hline Cases >= Test Value & 1173 & 1173 & 1174 & 1173 & 1173 \\
\hline Total Cases & 2345 & 2345 & 2345 & 2345 & 2345 \\
\hline Number of Runs & 55 & 12 & 22 & 39 & 35 \\
\hline $\mathbf{Z}$ & $-46.2^{* *}$ & $-47.9^{* *}$ & $-47.5^{* *}$ & $-46.8^{* *}$ & $-47.0^{* *}$ \\
\hline
\end{tabular}

*** Significant at $1 \%$ level

Table 5. Runs Above and Below the Mean Test

\begin{tabular}{|c|c|c|c|c|c|}
\hline & General & Banks & Insurance & Industry & Services \\
\hline Test Value & 150.3 & 192.9 & 129.8 & 113.5 & 121.4 \\
\hline Cases < Test Value & 1030 & 1223 & 1501 & 1056 & 1385 \\
\hline Cases > = Test Value & 1315 & 1122 & 844 & 1289 & 960 \\
\hline Total Cases & 2345 & 2345 & 2345 & 2345 & 2345 \\
\hline Number of Runs & 39 & 20 & 14 & 23 & 17 \\
\hline$Z$ & $-46.8^{* *}$ & $-47.6^{* *}$ & $-47.8^{* *}$ & $-47.5^{* *}$ & $-47.7^{* *}$ \\
\hline
\end{tabular}

${ }^{* *}$ Significant at $1 \%$ level 
Table 6. Runs Above and Below the Mode (1) Test

\begin{tabular}{|c|c|c|c|c|c|}
\hline & General & Banks & Insurance & Industry & Services \\
\hline Test Value & 160.7 & 216.7 & 122.8 & 117.0 & 100.2 \\
\hline Cases $<$ Test Value & 1597 & 1618 & 990 & 1257 & 172 \\
\hline Cases >= Test Value & 748 & 727 & 1355 & 1088 & 2173 \\
\hline Total Cases & 2345 & 2345 & 2345 & 2345 & 2345 \\
\hline Number of Runs & 41 & 22 & 44 & 45 & 39 \\
\hline $\mathbf{Z}$ & $-46.5^{* *}$ & $-47.4^{* *}$ & $-46.6^{* *}$ & $-46.6^{* *}$ & $-42.7^{* *}$ \\
\hline
\end{tabular}

${ }^{* *}$ Significant at $1 \%$ level

${ }^{(1)}$ There are multiple modes. The mode with the largest data value is used. 